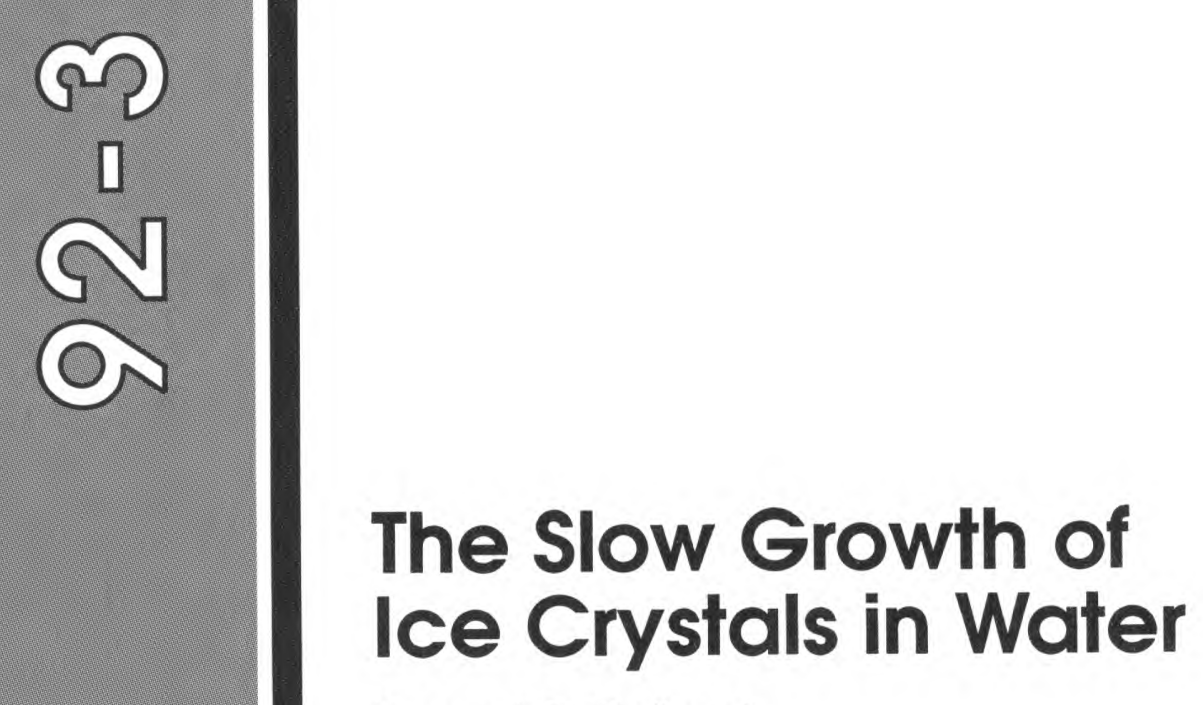

Samuel C. Colbeck
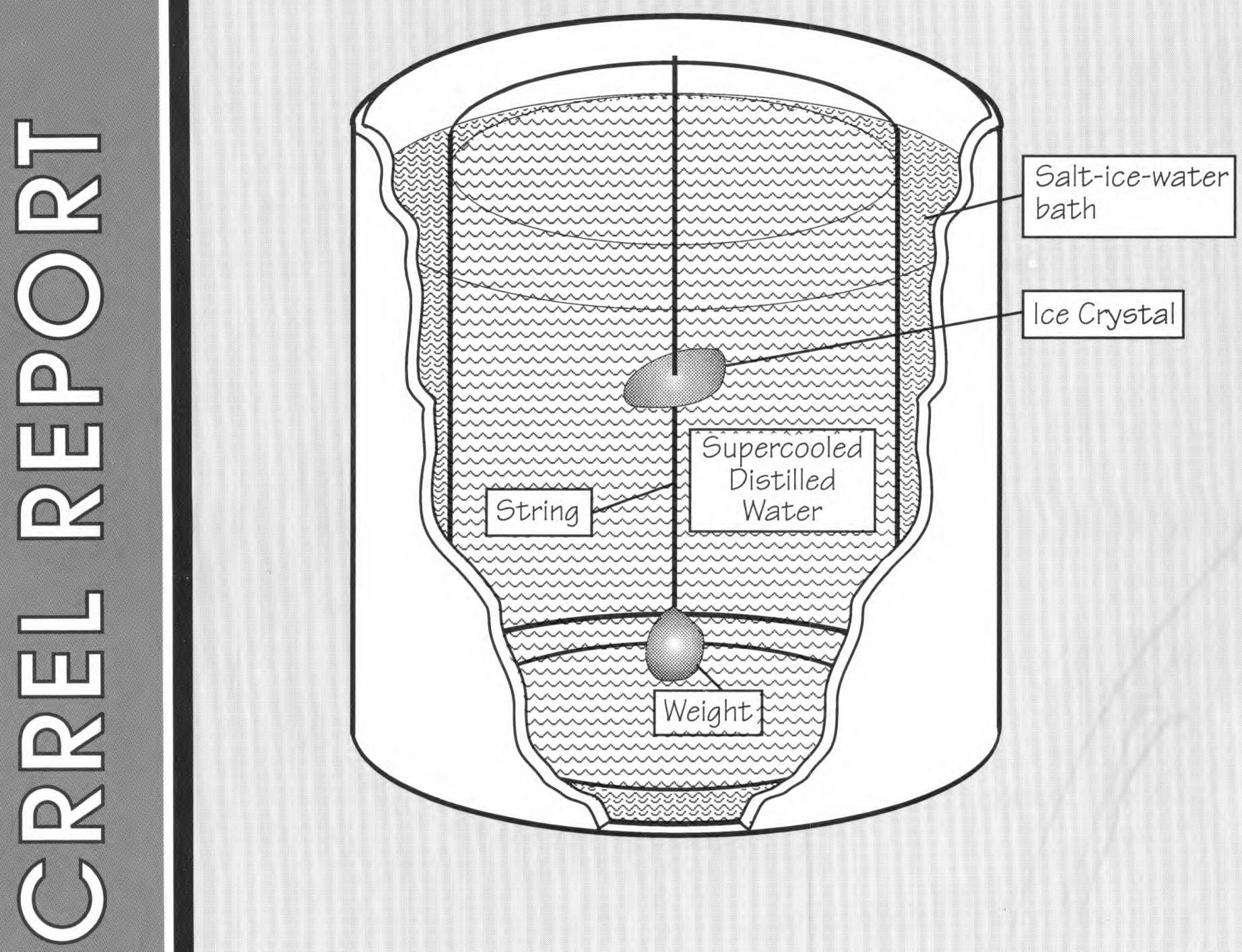
For conversion of SI metric units to U.S./British customary units of measurement consult ASTM Standard E380, Metric Practice Guide, published by the American Society for Testing and Materials, 1916 Race St., Philadelphia, Pa. 19103.

COVER: Experimental apparatus. 
CRREL Report 92-3

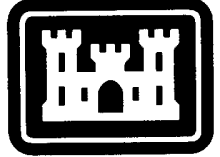

U.S. Army Corps of Engineers

Cold Regions Research \& Engineering Laboratory

\section{The Slow Growth of \\ Ice Crystals in Water}

Samuel C. Colbeck

March 1992 


\section{PREFACE}

This report was prepared by Dr. Samuel C. Colbeck, Research Geophysicist, Snow and Ice Branch, Research Division, U.S.A. Cold Regions Research and Engineering Laboratory. Funding was provided under In-House Laboratory Independent Research Project 4A161101A91D/576, Growth of Ice Crystals from Melt. The report was technically reviewed by Steven Daly of CRREL and Dr. H.T. Shen of Clarkson University. 


\title{
The Slow Growth of Ice Crystals in Water
}

\author{
SAMUEL C. COLBECK
}

\section{INTRODUCTION}

The growth of ice crystals is an important natural phenomenon and has led to many investigations of crystal growth. Most of the interest has been in the rapid growth of crystals from the vapor, such as in the atmosphere (e.g. Lamb and Scott 1974), but slow growth from the vapor has also received attention because of the importance of metamorphism in the seasonal snow cover (Colbeck 1983). Ice crystal growth from the melt is important in nature but has received considerably less attention, especially over the range of growth rates that are important in wet snow or even in frazil ice in rivers. The slowest growth rates occur in wet snow when the snow cover is freely drained and most of the pore volume is occupied by air. Then the ice crystals bond together in clusters (Colbeck 1979), as shown in Figure 1.

There are two common situations where ice crystals grow while immersed in the melt. First, slush is water-saturated snow consisting of poorly bonded ice particles that grow to a size of about 1 $\mathrm{mm}$ in $24 \mathrm{hr}$. As shown in Figure 2, these particles are very well rounded, and they develop in a population with a log-normal distribution (Colbeck 1986). This arises from the dynamics of growth in a population of particles competing among themselves due to slight curvature differences. The second common situation is frazil ice particles, which are rapidly growing disks (Fig. 3). These crystals grow only in turbulent, supercooled water, which is common in streams and rivers in winter. They grow at supercoolings of about $0.01^{\circ} \mathrm{C}$ with a concentration of about $10^{6}$ per $\mathrm{m}^{3}$ (Daly and Colbeck 1986). The mechanism of their growth is very different from that in slush because the crystals are well separated, so each one has a large reservoir of supercooled water into which it loses heat. Furthermore, the turbulence should enhance the rate at which the growing crystals lose heat. Accordingly the growth rateis high and the crystals always develop as disks with sharp edges.

The growth of ice disks in water has been both observed and modeled (Hillig and Turnbull 1956, Hillig 1958, Bukina 1967, Pruppacher 1967, Daly and Colbeck 1986), with some interest in the stability of rapidly growing disks. Through thousands of observations of frazil disks, Daly and Colbeck (1986) never observed morphological instability except when the larger disks float to the air/water interface, probably because the growth rate of frazil is limited by the high concentration of crystals, which limits the supercooling. With supercoolings above $0.2^{\circ} \mathrm{C}$, ice crystals grow as dendrites (Hillig 1958), but the supercoolings during frazil growth are only about $0.01^{\circ} \mathrm{C}$.

The purpose here is to investigate the shape of ice crystals growing from the melt at the growth rates of interest in nature. This spans the range from slush, about $1 \times 10^{-6} \mathrm{~g} / \mathrm{hr}$ (Colbeck 1986), to that of frazil, about $3 \times 10^{-3} \mathrm{~g} / \mathrm{hr}$ (Daly and Colbeck 1986), and is accompanied by a dramatic change in morphology from disks at high growth rates to spheroids at low growth rates (Colbeck 1986).

Disks develop by growth along the a-axis of the ice crystal, with growth along the c-axis being slow due to a strong anisotropy in the interfacial growth kinetics. At a few degrees of supercooling, growth along the c-axis is about 100 times less than along the a-axis (Hallet 1968), and Hillig (1958) suggested that at supercoolings below $0.02^{\circ} \mathrm{C}$, growth along the c-axis essentially disappears. While this may be true for ice crystals grown in capillaries, it is not true for the growth of frazil ice, and slowly growing crystals in slush are not even disks. Accordingly we should be cautious about applying the results of crystals growth experiments to environments different from those of the experiment. 


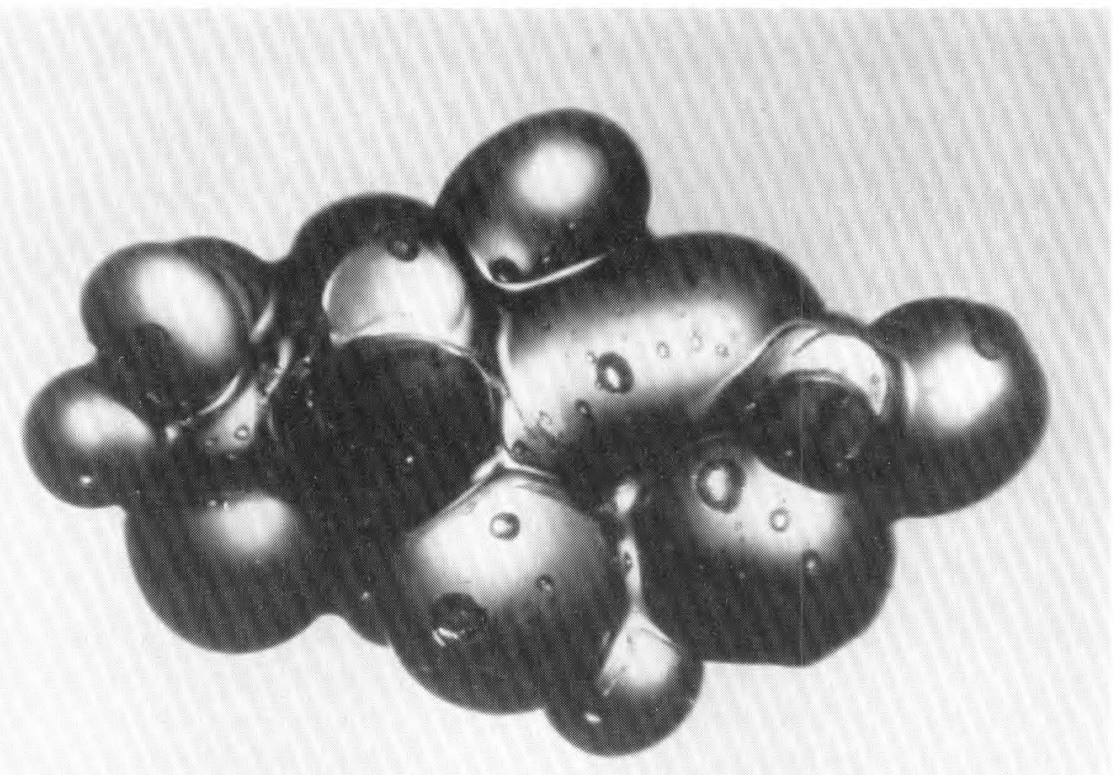

Figure 1. Cluster of ice crystals growing in snow with a low liquid content.

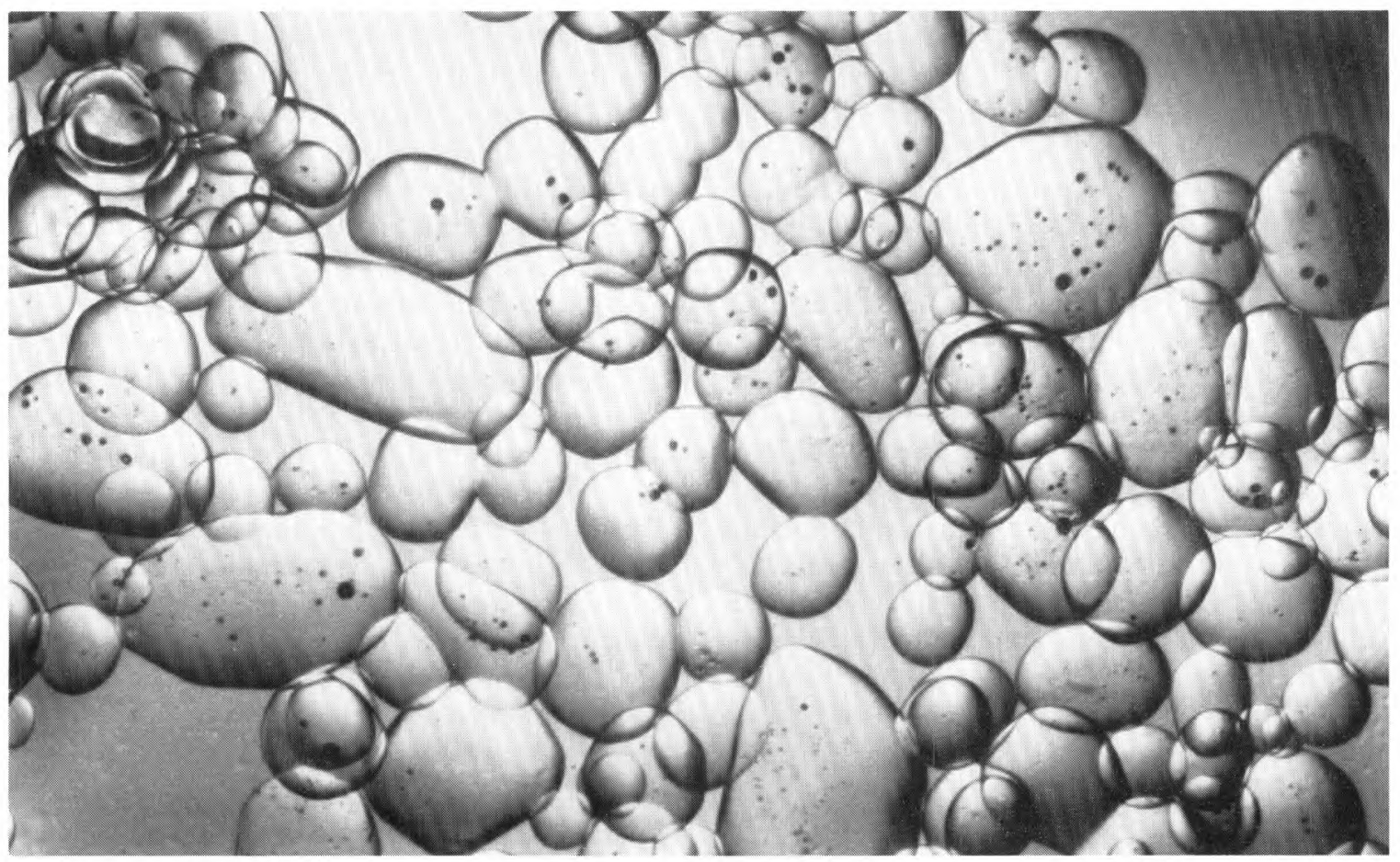

Figure 2. Ice crystals growing in water-saturated snow, or slush. These are typically poorly bonded, well rounded and about $1 \mathrm{~mm}$ in size. 


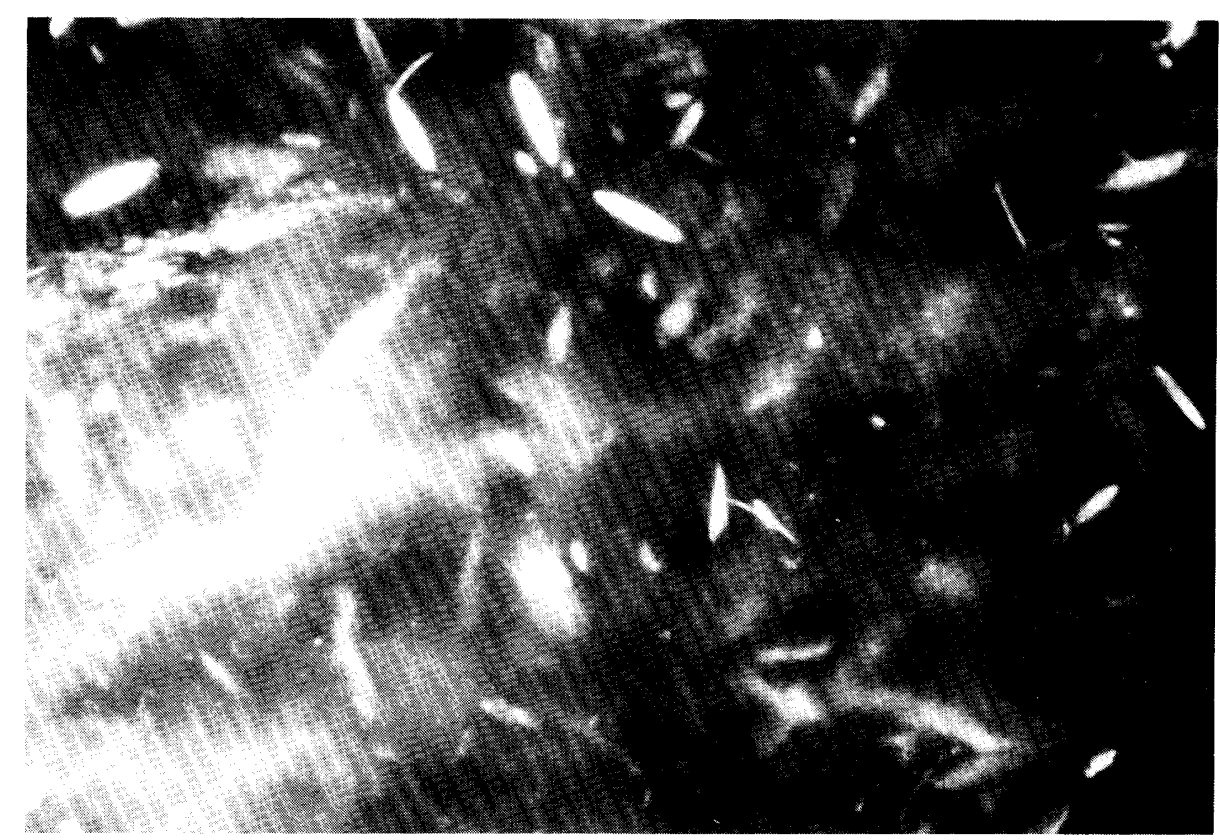

Figure 3. Frazil disks growing in turbulent water. These are typically sharp disks with no sign of interaction with other crystals. Some are blurred due to motion or obscured due to ice on the surface of the water.

During rapid growth for short periods of time, usually tens to hundreds of seconds for frazil crystals, the growth along the a-axis controls the morphology but with an aspect ratio of 10 or less, not 100 or less as suggested above. Futhermore, it is clear that during slow growth (tens of hours for slush) metamorphic processes due to curvature effects on the phase-equilibrium temperature are also important. In the next section we look at the theory of the growth of disk crystals and modify it to account for metamorphism. This is followed by some experimental observations of the growth of single crystals in the melt, at growth rates spanning the range from slush to frazil, to observe the effect of growth rate of morphology.

\section{THEORY}

We begin by looking at the established theories for disk growth and then add the effect of metamorphism due to curvature. Since a general theory accounting for all of the processes seems unattainable at this time, we will concentrate on a theory that allows us to think about two of the processes: the rapid growth of disks of a constant aspect ratio and the transition to the growth of rounded crystals. By analogy with the growth of ice crystals from the vapor (Colbeck 1983), in the melt we might also expect a sudden, rather than a gradual, transition between the growth of disks and well-rounded ice crystals.

\section{Disk growth}

The first attempts to model ice crystal growth in an infinite medium used the electrostatic analogy (Marshall and Langleban 1954), which simulates the potential field, in this case the temperature field, around the growing crystal. This leads to the simple result that, for pure diffusion,

$$
\dot{m}=\frac{4 \pi C k_{\mathrm{w}}}{L} \Delta T
$$

where $\dot{m}=$ mass growth rate

$4 \pi C=$ capacitance, which depends on the shape of the particle

$k_{\mathrm{w}}=$ thermal conductivity of water

$L=$ latent heat

$\Delta T=$ supercooling.

This approach was reviewed by Hallet (1968). Fujioka and Sekerka (1974) predicted a very differ- 
ent temperature field around a disk, one that shows strong temperature gradients only at the tip of the disk, thus accounting for the low growth rates on the faces.

Using the electrostatic approach for a disk, the growth rate for constant thickness is

$$
\frac{\mathrm{d} a}{\mathrm{~d} t}=\frac{2 k_{\mathrm{w}} \Delta T}{\pi b L \rho_{\mathrm{i}}}
$$

where $a=$ radius

$$
\begin{aligned}
2 b & =\text { thickness of the disk } \\
\rho_{\mathrm{i}} & =\text { density of ice } \\
t & =\text { time. }
\end{aligned}
$$

Using their more sophisticated approach, Fujioka and Sekerka (1974) found that the disk grows as

$$
\frac{\mathrm{d} a}{\mathrm{~d} t}=\frac{\pi k_{\mathrm{w}}}{b L \rho_{\mathrm{i}}} \frac{\Delta T}{\ln (8 \mathrm{e} a / b)} .
$$

These two equations predict similar growth rates for the aspect ratios $(a / b)$ of interest here, but both need to be tested with the appropriate experiments. The observed grow th of frazil disks and the experimental observations reported here both suggest that disks thicken as they grow, and thus we extend the theory to the case of a constant aspect ratio. This simply reduces the growth rate given in eq 2 by about one-third, which is not a major change since the equation may only be qualitatively correct anyway. However, the model of a constant aspectratio is probably more realistic than that of a constant thickness over the range of growth rates of interest here. The major difference between the two results is that eq 2 predicts a linear increase in disk diameter with time, whereas, if the disk thickens as it grows, the diameter should increase as $t^{1 / 2}$. The result given by eq 3 falls between these two results, but the assumption of a constant disk thickness is not acceptable at the growth rates of interest here. Because of uncertainty over how good these approximations might be, the models provide only qualitative help for our thinking about slow crystal growth from the melt.

\section{Crystal metamorphism}

The effect of curvature on phase-equilbrium thermodynamics is important when the particles are very small or the growth rates are very slow or both. The resulting metamorphism of ice crystals is especially rapid in the melt because the temperature is high and phase change is not rate-limited by the relatively slow process of mass diffusion. Nevertheless, only the slower-growing slush crystals are well rounded, while the faster-growing frazil crystals are distinctly disk-shaped.

A simple model of the rounding of a particle by metamorphism is constructed here to estimate the magnitude of this effect on the shape of growing crystals of varying growth rates. Consider a crystal growing with the shape of an oblate spheroid, such as that shown in Figure 4. At the tip, where the curvature is high, the melting temperature is low; on the face, where the curvature is low, the melting temperature is high. Therefore, heat flows from the face to the tip, with a consequent

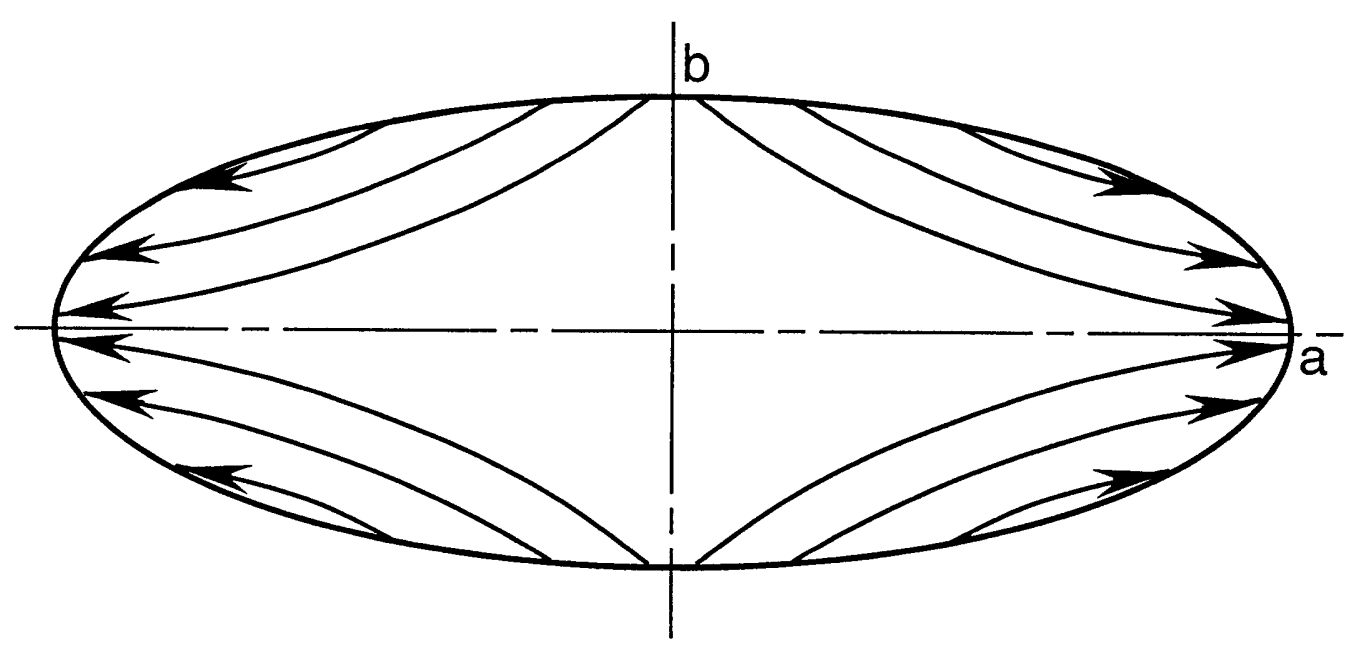

Figure 4. Model of an ice crystal undergoing metamorphism. This oblate spheroid would melt at the edge and grow on the face as it becomes rounder. 
loss of ice from the tip and gain on the face. By this mechanism the crystal is rounded such that, if this process is fast enough, disks would become spherelike. However, if the rate at which this process takes place is much smaller than the rate of growth along the a-axis, the shape will be determined by the kinetics of the growth process and metamorphism can be ignored. With the model of this process constructed here, an attempt is made to determine if metamorphism is important over this range of growth rates.

The temperature difference $\Delta T_{\mathrm{m}}$ driving the metamorphic process can be approximated by

$$
\Delta T_{\mathrm{m}}=\frac{2 T_{0} \sigma}{\rho_{\mathrm{i}} L}\left(\frac{1}{b}-\frac{1}{a}\right)
$$

where $T_{0}=$ melting temperature

$\sigma=$ ice-water interfacial energy

$a$ and $b=$ major and minor axes of the spheroid and the $b / a$ ratios come from the curvatures of a spheroid on the major and minor axes. The phase change and thickening are balanced when

$$
2 \pi a^{2} L \rho_{\mathrm{i}} \frac{\mathrm{d} B}{\mathrm{~d} t}=\pi a b q
$$

where $d B / d t$ is the thickening rate due to metamorphism only. The heat flow $q$ is approximately $2 k_{\mathrm{i}} \Delta T_{\mathrm{m}} / a$, where $k_{\mathrm{i}}$ is the thermal conductivity of ice. The rate of thickening due to metamorphism, or alternatively the rate of shrinking of the diameter of the spheroid $\mathrm{d} A / \mathrm{d} t$, is then given by

$$
\frac{\mathrm{d} A}{\mathrm{~d} t}=-\frac{k_{\mathrm{i}} T_{0} \sigma}{\left(\rho_{\mathrm{i}} \mathrm{L}\right)^{2}} \frac{1}{a^{2}}\left(\frac{a}{b}-1\right) .
$$

This suggests that metamorphism is important when the aspect ratio $a / b$ is large or when the disk is small or both. Thus large, rapidly growing disks should not experience metamorphism because of the long heat flow path along their length. Also, for large, rapidlygrowing disks, the temperature field calculated by Fujioka and Sekerka (1974) would overwhelm this effect. However, for slow growth rates the effect is important, as will be shown later.

\section{EXPERIMENTS}

Suspended ice crystals were grown in pure water at growth rates that spanned the range from those for slush to those for frazil. These rates were achieved by suspending small ice seeds on a nylon string in pure water, which itself was surrounded by a saline, ice-water bath. The supercooling of the pure water and therefore the growth rates of the suspended crystals increased with the salinity of the ice-water bath. However, the crystal growth rate and the salinity are not highly correlated because multiple crystals grew from the seeds, not just one crystal, as was desired. Also, the supercooling was not measured directly since it was too low to resolve accurately $\left(-0.001\right.$ to $\left.-0.05^{\circ} \mathrm{C}\right)$, but it was calculated from the measured salinity of the ice-water bath. As a result the quality of the data given in Table 1 is poor, but the trend to larger disks with larger aspect ratios can clearly be seen, just as expected from the observed differences between slush and frazil. The most rapidly growing disks (e.g. Fig. 5) had the highest aspect ratios, and the slowest growing ones (e.g. Fig. 6) had the lowest aspect ratios. All of the crystals were disks; the slower growing ones were not sphere-like, which was expected because the growth rate of at least one disk was in the range of slush. Likewise, the more rapidly growing disks had a wide range of aspect ratios and were not confined to the fairly narrow range found for frazil (Daly and Colbeck 1986).

The average growth rate $\overline{\mathrm{d} m / \mathrm{d} t}$ was computed from the final thickness and diameter of each disk $\left(2 b_{\mathrm{f}}, d_{\mathrm{f}}\right)$ and length of each test; this is shown in Figure 7 vs $d_{\mathrm{f}} \Delta T$. This data set is reasonably described by

$$
\overline{\mathrm{d} m / / \mathrm{d} t}=0.00296 d_{\mathrm{f}} \Delta T
$$

with an $r^{2}$ of 0.86 . However, the observed growth rates are significantly less than expected from the electrostatic theory for disks with a constant aspect ratio, which is also shown on Figure 7. The expected growth rate was calculated by integrating eq 1 over the growth period and assuming that the final diameter was twice its average value. Much of the difference between expected and observed sizes is probably due to competition among the growing crystals, as described above. Unfortunately this suggests caution in use of $\Delta T$ as a parameter in interpreting these results, but other results based on shape and size should still be useful. Since the crystals did not grow into semiinfinite surroundings but tended to grow while crowded by neighbors, there is no clear effect of $\Delta T$.

Several crystals were recovered and measured at most supercoolings. The results shown in Figure 8 suggest that the average growth rate increased as about the fourth power of size. This is a 
Table 1. Measured values.

\begin{tabular}{|c|c|c|c|c|c|}
\hline $\begin{array}{c}\text { Diameter } \\
(\mathrm{mm})\end{array}$ & $\begin{array}{c}\text { Thickness } \\
\text { (mm) }\end{array}$ & $\begin{array}{c}\text { Time } \\
(h r)\end{array}$ & $\begin{array}{l}\Delta \mathrm{T} \\
\left({ }^{\circ} \mathrm{C}\right)\end{array}$ & $\begin{array}{c}\overline{\dot{\mathrm{m}}} \times 10^{5} \\
(\mathrm{~g} / \mathrm{hr})\end{array}$ & Aspect \\
\hline 8.21 & 0.235 & 44.75 & - & 25.5 & 34.9 \\
\hline 2.03 & 0.760 & 49.75 & - & 4.53 & 2.67 \\
\hline 5.68 & 0.604 & 65.00 & - & 21.60 & 9.40 \\
\hline 4.58 & 0.703 & 192.0 & 0.0104 & 5.51 & 6.51 \\
\hline 3.92 & 0.600 & 192.0 & 0.0104 & 3.45 & 6.53 \\
\hline 4.865 & 0.5305 & 192.0 & 0.0104 & 4.71 & 9.17 \\
\hline 2.25 & 0.5068 & 192.0 & 0.0104 & 0.963 & 4.44 \\
\hline 1.10 & 0.4932 & 192.0 & 0.0104 & 0.222 & 2.22 \\
\hline 4.90 & 1.04 & 314.0 & 0.00225 & 5.29 & 4.71 \\
\hline 2.77 & 1.23 & 314.0 & 0.00225 & 2.14 & 2.25 \\
\hline 3.54 & 0.833 & 314.0 & 0.00225 & 2.39 & 4.25 \\
\hline 7.20 & 0.625 & 314.0 & 0.00225 & 7.45 & 11.52 \\
\hline 3.01 & 0.411 & 263.5 & 0.00143 & 1.021 & 7.33 \\
\hline 3.22 & 0.6575 & 263.5 & 0.00143 & 1.86 & 4.90 \\
\hline 3.625 & 0.370 & 263.5 & 0.00143 & 1.33 & 9.80 \\
\hline 3.40 & 0.616 & 263.5 & 0.00143 & 1.95 & 5.52 \\
\hline 4.43 & 0.677 & 27.0 & 0.0470 & 35.5 & 6.55 \\
\hline 13.0 & 0.492 & 27.0 & 0.0470 & 223.0 & 26.5 \\
\hline 2.06 & 0.447 & 90.0 & 0.0302 & 1.517 & 4.60 \\
\hline 4.71 & 0.581 & 90.0 & 0.0302 & 10.32 & 8.10 \\
\hline 4.41 & 0.512 & 90.0 & 0.0302 & 7.95 & 8.61 \\
\hline 3.545 & 0.465 & 90.0 & 0.0302 & 4.68 & 7.62 \\
\hline 2.75 & 0.329 & 53.5 & 0.023 & 3.34 & 8.35 \\
\hline 3.175 & 0.235 & 53.5 & 0.023 & 3.19 & 13.5 \\
\hline 2.42 & 0.329 & 53.5 & 0.023 & 2.60 & 7.36 \\
\hline 2.43 & 0.513 & 53.5 & 0.023 & 4.08 & 4.74 \\
\hline 2.76 & 0.184 & 53.5 & 0.023 & 1.89 & 15.00 \\
\hline 3.26 & 0.290 & 53.5 & 0.023 & 4.13 & 11.25 \\
\hline
\end{tabular}

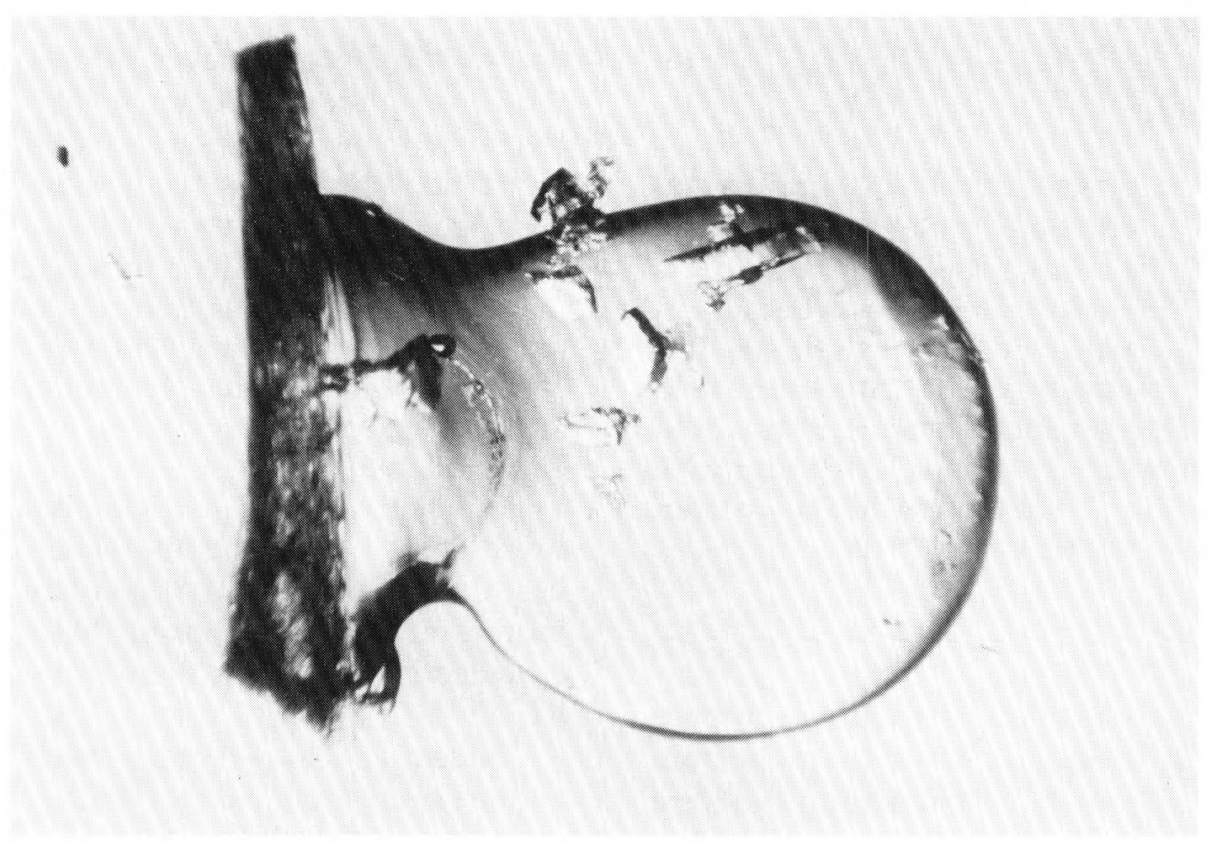

Figure 5. Rapidly growing disk crystal in these experiments. 


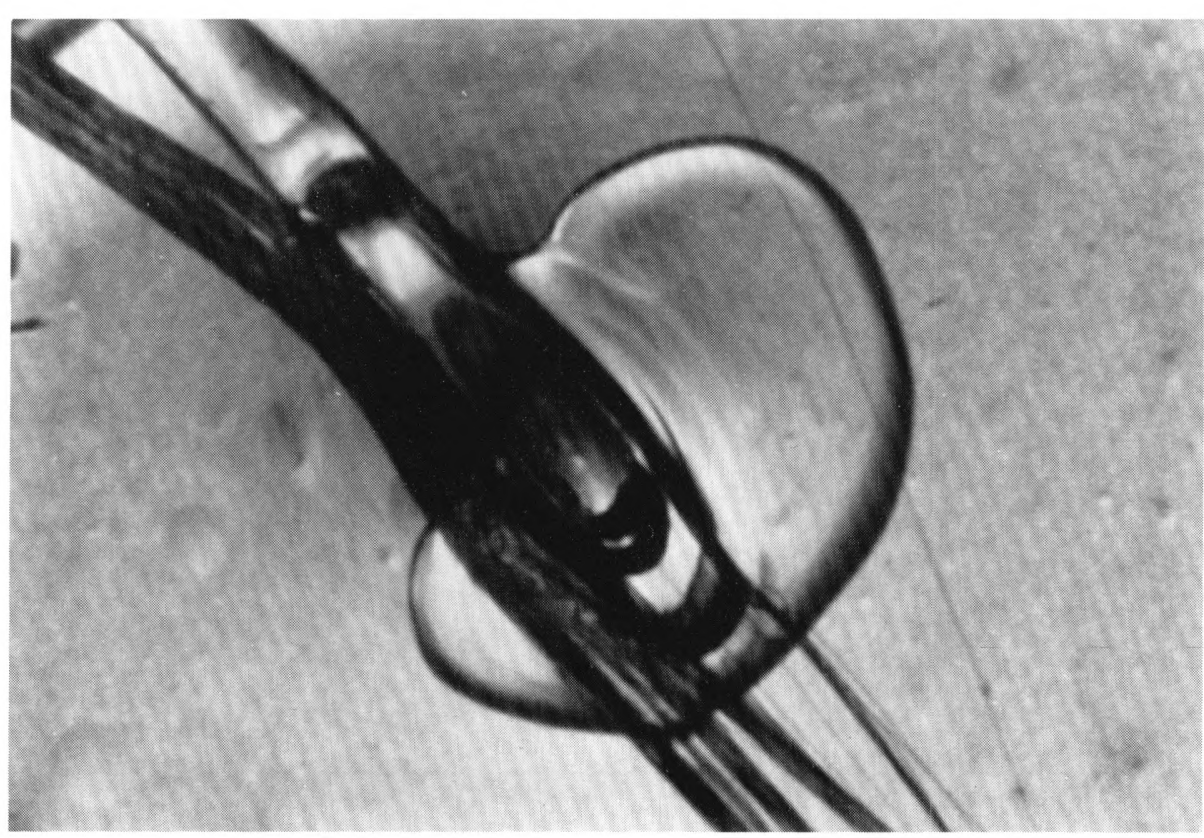

Figure 6. Slowly growing disk crystal in these experiments.

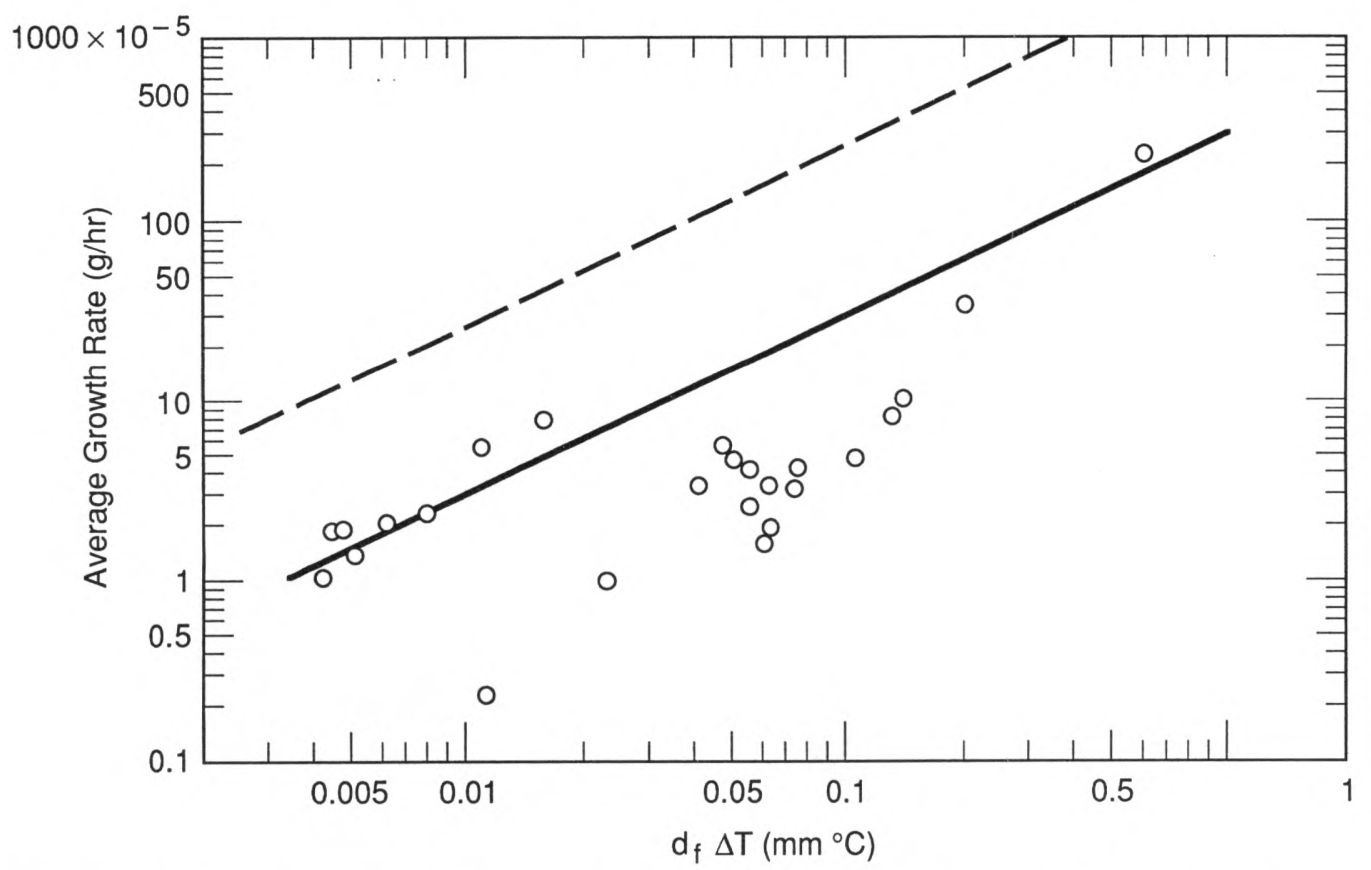

Figure 7. Average mass growth rate vs the product of size and $\Delta \mathrm{T}$. The data are described by a leastsquares fit, with $\mathrm{r}^{2}$ of 0.86 . The theoretically derived line is also shown. 


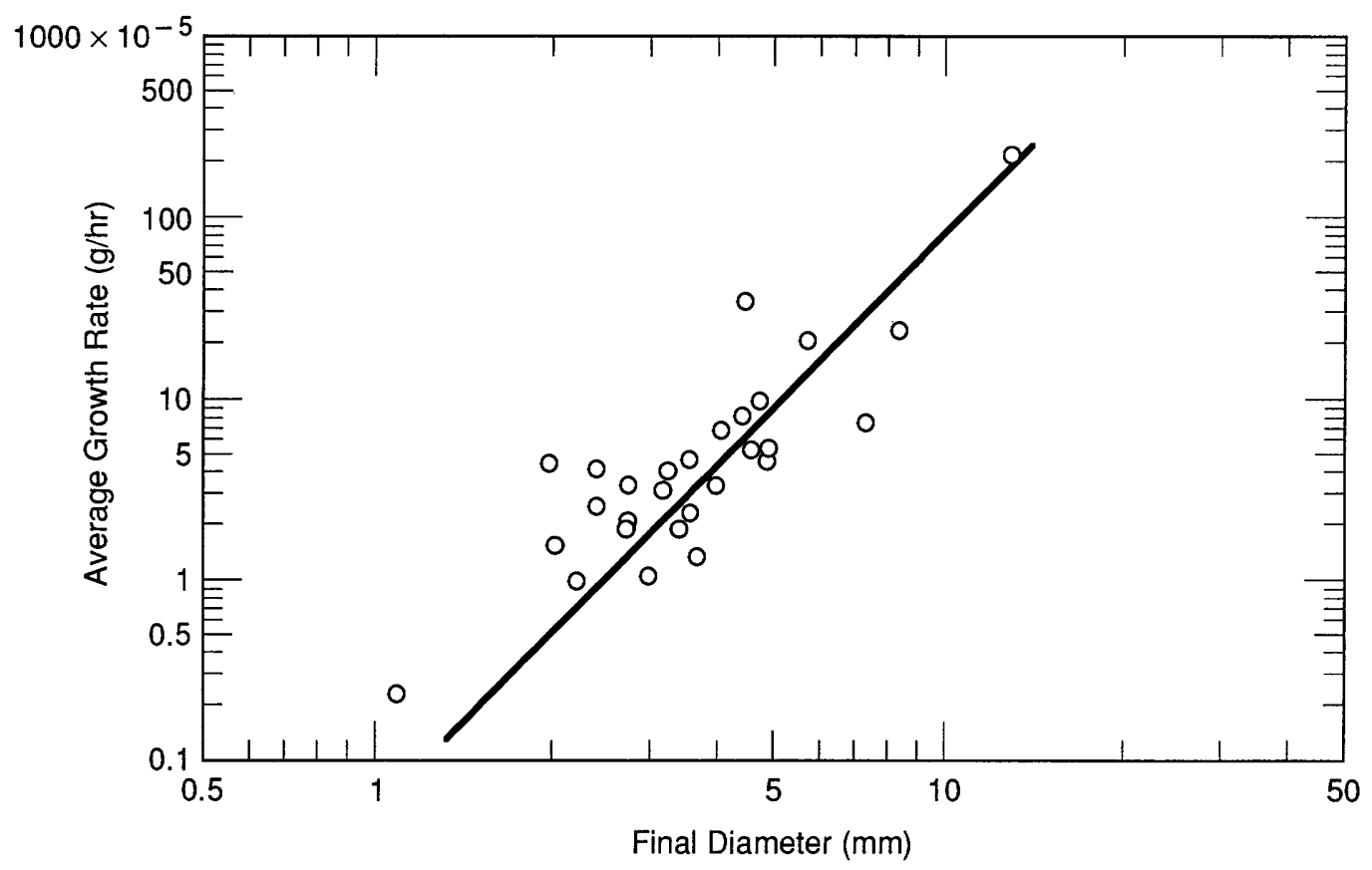

Figure 8. Average mass growth rate vs size. The data are described by a least-squares fit, with $\mathrm{r}^{2}$ of 0.97 .

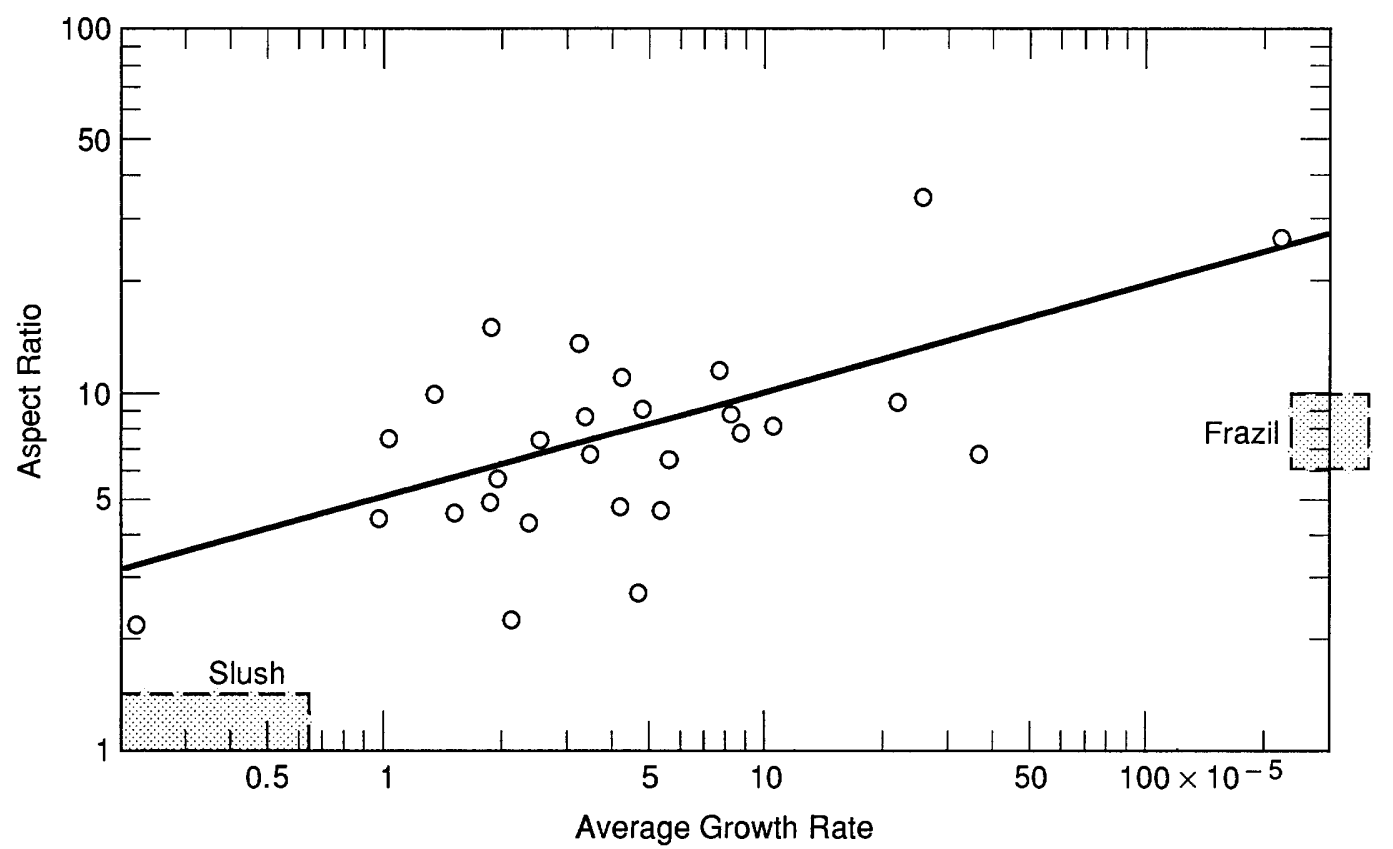

Figure 9. Aspect ratio vs average mass growth rate. The observed ranges for slush and frazil are shown, and the data are described by a least-squares fit, with $\mathrm{r}^{2}$ of 0.78 . 


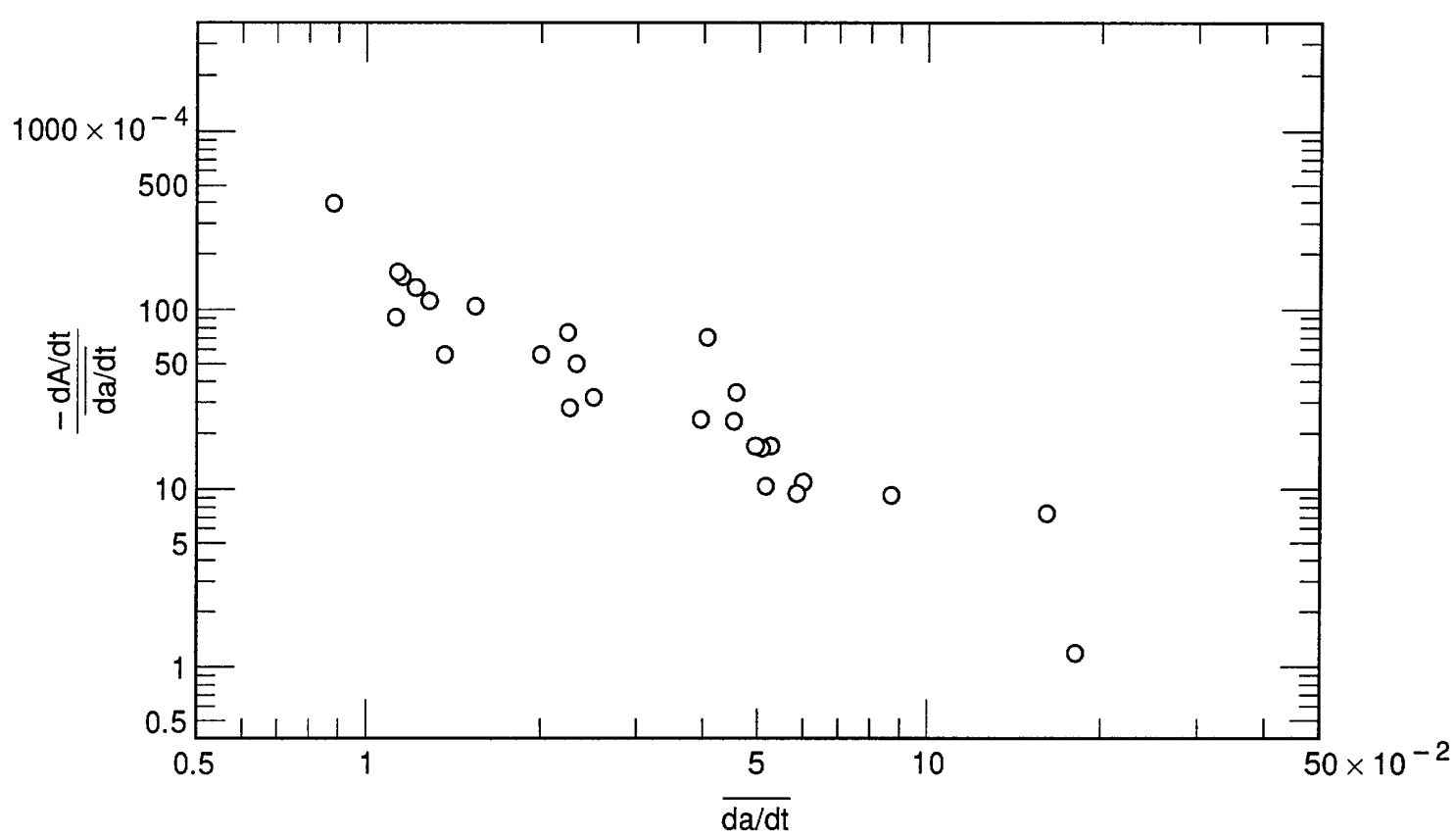

Figure 10. Ratio of metamorphic growth rate to average growth rate vs average growth rate.

much stronger dependence on size than is suggested by eq 1 . The result should be viewed with some caution, however, since it is highly dependent on one crystal. If the largest crystal is ignored, the dependence on crystal size decreases markedly.

Figure 9 shows that aspect ratio increased with growth rate and shows the approximate regions into which slush and frazil would fall. However, there is no clear distinction between rapidly growing disks and slowly growing spheres, as might be expected from observations of slush and frazil and as was observed for growth from the vapor (Colbeck 1983). Although one crystal grew at a rate similar to that of slush, it was clearly diskshaped with an aspect ratio of over two; it had rounded edges but had distinctive flat faces. While even the most rapidly growing crytals had rounded edges, frazil crystals are generally quite sharp. Thus, simulation of the growth of either slush or frazil was imperfect using this technique.

From eq 6 we expect that metamorphism should be relatively important for the smallest crystals. This is clearly shown in Figure 10, where the ratio of metamorphic shrinking to measured growth rate is plotted vs measured growth rate. This ratio increases as the growth rate decreases but never approaches a value of one in the lower range of growth rates from the experimental results. Thus, even for particles growing in the range of slush crystals, the rate of thickening due to metamorphism appears to have no effect on the overall growth characteristics of the particles, so the kinetics of crystal growth must control the shape of crystals over this entire range of growth rates. Again, there is no suggestion of a sudden transition from disk growth to sphere-like growth.

\section{CONCLUSION}

Ice crystals were grown on a line suspended in supercooled water at rates spanning the range from those of slush to those of frazil ice. Their growth should be described by the classic theory for crystal growth in an infinite medium, but the theory overpredicts the growth rate, probably because multiple crystals grew at each location in the supercooled water. A simple model of crystal thickeningby metamorphism wasalso constructed, and this suggests that the crystals do not thicken by this mechanism, even at the lowest growth rates observed. Thus, thickening by curvaturecontrolled metamorphism is not important for the crystals grown here, although it does appear to be important in the crowded environment in which 
slush grows. The aspect ratio increased with growth rate, as was expected from observations of slush and frazil, but there was no sharp transition between them, as is observed with vaporgrown crystals. The aspect ratios observed in these experiments were larger than expected in the growth ranges for both slush and frazil. While these experiments were somewhat successful in simulating the growth of frazil and slush crystals, some cleardepartures from both theory and observations in nature were noted. These might be changed by a more carefully controlled set of experiments where only one crystal grew from each seed and where the slight supercoolings were measured. However, it could also indicate a failure of the theory, which has never before been tested.

\section{LITERATURE CITED}

Bukina, L.A. (1967) Size distribution of frazil ice crystals in turbulent flows. Izv., Atmospheric and Oceanic Physiology, 3(1): 58-68.

Colbeck, S.C. (1979) Grain clusters in wet snow. Journal of Colloid and Interface Science, 72(3):371-384.

Colbeck, S.C. (1983) Ice crystal morphology and growth rates at low supersaturations and high temperatures. Journal of Applied Physiology, 54(5): 2677-2682.

Colbeck, S.C. (1986) Statistics of coarsening in water-saturated snow. ActaMetallurgica,34(3):347353.

Daly, S.F. and S.C. Colbeck (1986) Frazil ice measurements in CRREL's flume facility. In IAHR Ice Symposium, vol. 1, p. 427-438.

Fujioka, T. and R.F. Sekerka (1974) Morphologicalstability of disccrystals. Journal of Crystal Growth, 24/25: 84-93.

Hallet, J. (1968) Nucleation and growth of ice crystals in water and biological systems. In Low Temperature Biology of Foodstuffs (J. Hawthorn and E.J. Rolfe, Ed.). Oxford: Pergamon Press, p. 23-52.

Hillig, W.B. (1958) The kinetics of freezing in ice in the direction perpendicular to the basal plane. In Growth and Perfection of Crystals (R.H. Doremus, B.W. Roberts and D. Turnbull, Ed.). New York: Wiley, p. 350-360.

Hillig, W.B. and D. Turnbull (1956) Theory of crystal growth in undercooled pure liquids. Journal of Chemical Physiology, 24(4): 914.

Lamb, D. and W.D. Scott (1974) The mechanism of ice crystal growth and habit formation. Journal of Atmospheric Science, 31(2): 570-580.

Marshall, J.S. and M.P. Langleben (1954) A theory of snow-crystal habit and growth. Journal of Meteorology, 11(2): 104-120.

Pruppacher, H.R. (1967) Some relations between the structure of the ice-solution interface and the free growth rate of ice crystals in supercooled aqueous solutions. Journal of Colloid and Interface Science, 25: 285-295. 
Public reporting burden for this collection of information is estimated to average 1 hour per response, including the time for reviewing instructions, searching existing data sources, gathering and maintaining the data needed, and completing and reviewing the collection of information. Send comments regarding this burden estimate or any other aspect of this collection of information, including suggestion for reducing this burden, to Washington Headquarters Services, Directorate for Information Operations and Reports, 1215 Jefferson Davis Highway, Suite 1204, Arlington, VA 22202-4302, and to the Office of Management and Budget, Paperwork Reduction Project (0704-0188), Washington, DC 20503.

\begin{tabular}{|l|c|c|}
\hline 1. AGENCY USE ONLY (Leave blank) & $\begin{array}{c}\text { 2. REPORT DATE } \\
\text { March } 1992\end{array}$ & 3. REPORT TYPE AND DATES COVERED \\
\hline
\end{tabular}

4. TITLE AND SUBTITLE

The Slow Growth of Ice Crystals in Water

ILIR

6. AUTHORS

Samuel C. Colbeck

PR: 4A161101A91D/576

7. PERFORMING ORGANIZATION NAME(S) AND ADDRESS(ES)

U.S. Army Cold Regions Research and Engineering Laboratory

72 Lyme Road

Hanover, N.H. 03755-1290

9. SPONSORING/MONITORING AGENCY NAME(S) AND ADDRESS(ES)

10. SPONSORING/MONITORING

AGENCY REPORT NUMBER

Office of the Chief of Engineers

Washington, D.C. 20314

8. PERFORMING ORGANIZATION REPORT NUMBER

CRREL Report 92-3

11. SUPPLEMENTARY NOTES

12a. DISTRIBUTION/AVAILABILITY STATEMENT

Approved for public release; distribution is unlimited.

Available from NTIS, Springfield, Virginia 22161. 12b. DISTRIBUTION CODE

UL

13. ABSTRACT (Maximum 200 words)

Ice crystals were slowly grown in supercooled water at growth rates spanning those for slush to those for frazil. All of the crystals were disks with aspect ratios between 2 and 35, which increased with growth rate. The growth rates were much less than expected from theory, possibly because of crowding in the experiment. The shapes showed a gradual transition from well rounded to highly faceted as the growth rate increased. Even in the lower range of growth rates the crystals do not undergo metamorphism during growth, so the kinetics of crystal growth controls the shape over the entire range of growth rates investigated here. This explains why all of the crystals were disk shaped, as opposed to the well-rounded crystals seen in slush.

\begin{tabular}{|c|c|c|c|c|}
\hline \multirow[t]{2}{*}{ 14. SUBJECT TERMS } & \multirow{2}{*}{$\begin{array}{l}\text { Crystal growth } \\
\text { Frazil }\end{array}$} & \multirow{2}{*}{\multicolumn{2}{|c|}{$\begin{array}{l}\text { Ice } \\
\text { Slush }\end{array}$}} & \begin{tabular}{|c} 
15. NUMBER OF PAGES \\
16 \\
\end{tabular} \\
\hline & & & & 16. PRICE CODE \\
\hline $\begin{array}{l}\text { 17. SECURITY CLASSIFICATION } \\
\text { OF REPORT }\end{array}$ & \multicolumn{2}{|c|}{$\begin{array}{l}\text { 18. SECURITY CLASSIFICATION } \\
\text { OF THIS PAGE }\end{array}$} & $\begin{array}{l}\text { 19. SECURITY CLASSIFICATION } \\
\text { OF ABSTRACT }\end{array}$ & 20. LIMITATION OF ABSTRACT \\
\hline UNCLASSIFIED & \multicolumn{2}{|c|}{ UNCLASSIFIED } & UNCLASSIFIED & $\mathrm{UL}$ \\
\hline
\end{tabular}

